\title{
Magnetic Measurements of the Injector Synchrotron Magnets for the Advanced Photon Source
}

\author{
S. H. Kim, D. W. Camegie, C. L. Doose, R. Hogrefe, K. Kim, R. Merl and L. R. Turner \\ Argonne National Laboratory \\ Argonne, Illinois 60439-4815
}

\begin{abstract}
The magnetic measurement data of the dipole, quadrupole, and sextupole magnets for the Advanced Photon Source Injector synchrotron are summarlzed. Magnet design and magnetlc measurements of the fleld strength, fleld shape, and multipole coefficients are described.
\end{abstract}

\section{INTRODUCTION}

The 7-GeV Advanced Photon Source (APS) is a national facility dedicated to highly-brilliant synchrotron radiation research [1]. The injector synchrotron (IS) of the APS accelerates the positron beam, which is extracted from the positron accumulator ring, from $0.45 \mathrm{GeV}$ to $7.0 \mathrm{GeV}$ of the beam energy with a ramp time of $0.25 \mathrm{~s}$, and then injects the beam into the storage ring with a repetition rate of $2 \mathrm{~Hz}$. The IS ring has a circumference of $368.0 \mathrm{~m}$ with 40 sectors of focusing-defocusing lattice. The ring requires 68 dipole, 80 quadrupole (quad), and 64 sextupole (sext) magnets which are linearly excited to accommodate the energy of the positron beam. The main parameters for the ring magnets are listed in Table 1.

TABLE 1

PARAMETERS FOR THE IS RING MAGNETS

\begin{tabular}{|c|c|c|c|}
\hline & Dipole & Quad & Sext \\
\hline \# of Magnet & 68 & 80 & 64 \\
\hline Magnetic Length & 3.077 & 0.5 & 0.12 \\
\hline $\begin{array}{l}\text { Pole Gap or Bore Dia. } \\
\text { (mm) }\end{array}$ & 40.0 & 56.56 & 70.0 \\
\hline \multicolumn{4}{|l|}{ Field Strength at } \\
\hline $0.45 \mathrm{GeV}$ & $0.045 \mathrm{~T}$ & $0.96 \mathrm{~T} / \mathrm{m}$ & $8.8 \mathrm{~T} / \mathrm{m}^{2}$ \\
\hline Current (A) & 60 & 39 & 4 \\
\hline $0.70 \mathrm{GeV}$ & $0.701 \mathrm{~T}$ & $6.6 \mathrm{~T} / \mathrm{m}$ & $248.0 \mathrm{~T} / \mathrm{m}^{2}$ \\
\hline Current (A) & 930 & 600 & 116 \\
\hline Steel Mass/Magnet (kg) & 1793 & 237 & 20.7 \\
\hline \# Turns/Coil & 12 & 9 & 10 \\
\hline Coil Inductance $(\mathrm{mH})$ & 6.6 & 1.14 & 0.42 \\
\hline Coil Resistance $(\mathrm{n} \Omega)$ & 16.7 & 18.5 & 31.9 \\
\hline
\end{tabular}

Manuscript received September 20,1993. This work was supported by the U.S. Department of Energy, Office of Basic Energy Sciences, under Contract No. W-31-109-ENG-38.
The magnet cross sections are symmetrical and designed to allow easy installation of the stainless steel vacuum chamber by lifting the upper half of the magnets. The $1.52-\mathrm{mm}$-thick laminations used for the core of the magnets are of lowcarbon steel with coercive force less than $1.0 \mathrm{Oe}$. The laminations are coated on both sides with a $13-\mu \mathrm{m}$-thick "Bstage" epoxy. After finding no appreciable eddy current effects for the ramping rate, the production magnets are measured in a DC mode at selected ex citation currents.

The normal and skew multipole field coefficients, $b_{\mathfrak{n}}$ and $a_{n}$, for a 2-D magnetic field, $B=B_{y}+i B_{x}$, are defined

$$
B \ell=B_{\alpha} \sum_{n=0}^{\infty}\left(b_{n}+i a_{n}\right)\left[(x+i y) / r_{0}\right]^{n},
$$

where $\ell$ is the magnetic length for an integral measurement and the reference radius $r_{0}$ is $25 \mathrm{~mm}$. The coefficients are defined as $b_{0}=1.0$ and $a_{0}=0$ for a dipole, $b_{1}=1.0$ and $a_{1}=$ 0 for a quad, and $b_{2}=1.0$ and $a_{2}=0$ for a sext magnet.

\section{DIPOLE MAGNET}

The cross section of the dipole is shown in Fig. 1. The lamination core of the magnet is stacked with a bending radius of $33.301 \mathrm{~m}$. Two fiducial ball bases for the "CERN balls" are welded on the top of the magnet. Two "alignment notches" along the magnet are used for the measurements of the roll angle. The allowed relative tolerances are: $1 \times 10^{-3}$ for the integrated vertical-field strength $\triangle B C / B \ell$, and $2.5 \times 10^{-4}$ and $6.2 \times 10^{-4}$ for the quad and sext coefficients, $b_{1}$ and $b_{2}$, respectively.

A general description of the magnetic measurement system is given in [2]. The production dipoles are measured with respect to a reference dipole by using two sets of integral coils, one fixed in the reference dipole and one for production dipoles. The integral-field strength, $B \ell$, and its variation with radial displacement are measured first by ramping up and down the excitation current, and then by moving the coil in the testing dipole in the transverse directions at a constant current. For the measurement of an average 2-D "body" field, $B_{0}$, a 15-m-long PC coil set is installed on top of the fullintegral coil.

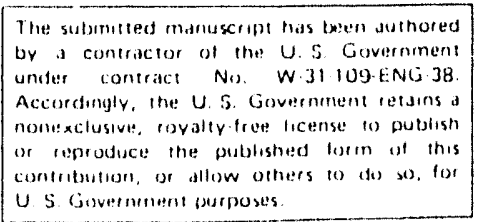


Plotted in Fig. 2 are the variations of the integral and 2-D fields, $\triangle B C$ and $\Delta B_{0}$, relative to the middle of the pole gap with the radial displacement in the midplane for the reference dipole. The variations at $60 \AA(0.45 \mathrm{GeV})$ and $930 \mathrm{~A}(7.0$ $\mathrm{GeV}$ ) are less than $2.5 \times 10^{-4}$ and $1.5 \times 10^{-4}$, respectively. From the least square fitting of the measured data within \pm 30 $\mathrm{mm}$ transverse position, the quadrupole and sextupole coefficients are calculated as $0.5 \times 10^{-4}$ and $-0.7 \times 10^{-4}$, respectively.

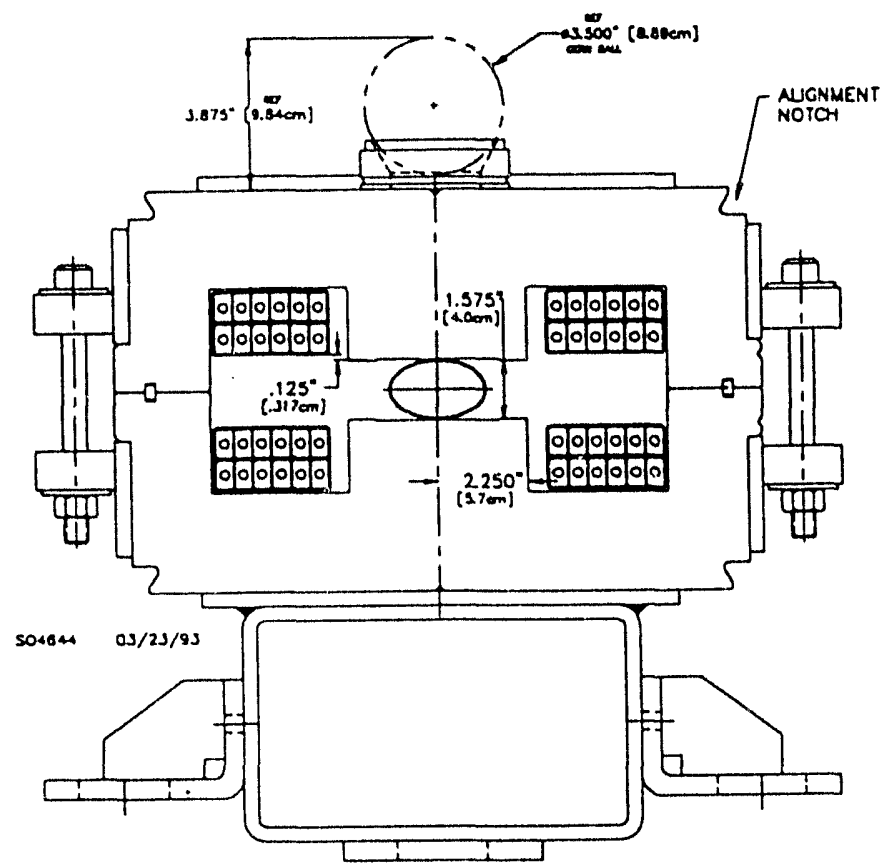

Fig. 1. Cross section of the dipole magnet.



Fig. 2. Integrated and 2.D field shapes for a dipole at $930 \mathrm{~A}$.
The pole-end bevels are designed so that the ratio of $\mathrm{B} C$ to $B_{0}$ does not vary with radial displacement. The end-field shapes are measured with a 0.5 -m-long coil extending $0.25 \mathrm{~m}$ outside the core end. The 3-D computations using TOSCA agree with the measurements to within $1 \times 10^{-3}$ [3].

The magnetic measurement data and allowed tolerances for the 68 dipoles are summarized in Table 2. It is seen that the rms of $\triangle B l / B \ell$ for all dipoles is far less than the allowed tolerance. From the average integrated-field strength and 2-D field, $\langle\mathrm{B} \ell\rangle$ and $\left\langle\mathrm{B}_{0}\right\rangle$, the average magnetic length is calculated to $3091.6 \pm 0.13 \mathrm{~mm}$. The average residual ficld is $12.56 \pm 0.43 \mathrm{G}$. Plotted in Fig. 3 are variations of the relative $B \ell$ and $B_{0}$ for all dipoles. Except for a few dipoles, the relative field strength varies less than $1 \times 10^{-3}$.

TABLE 2

TOLERANCE AND MEASURED RMS FOR 68 IS DIPOLE MAGNETS

\begin{tabular}{ccc}
\hline & $\begin{array}{c}\text { Allowed } \\
\text { Tolerance }\end{array}$ & $\begin{array}{c}\text { Measured } \\
\text { rms @ 930A }\end{array}$ \\
\hline$\langle\Delta B C / B C\rangle$ & $1.0 \times 10^{-3}$ & $3.4 \times 10^{-4}$ \\
$\left\langle\Delta B_{0} / B_{O}\right\rangle$ & $\cdots$ & $1.2 \times 10^{-4}$ \\
$b_{1}$ & $2.5 \times 10^{-4}$ & $0.3 \times 10^{-4}$ \\
$b_{2}$ & $6.2 \times 10^{-4}$ & $0.5 \times 10^{-4}$ \\
\hline
\end{tabular}

*Least square fit for the data in the midplane.

The survey angle of a dipole is the difference between the angle at the survey reference position and the average angle for 20 measurements along the magnet length. The angles vary within $\pm 0.5 \mathrm{mrad}$ along the longitudinal positions.

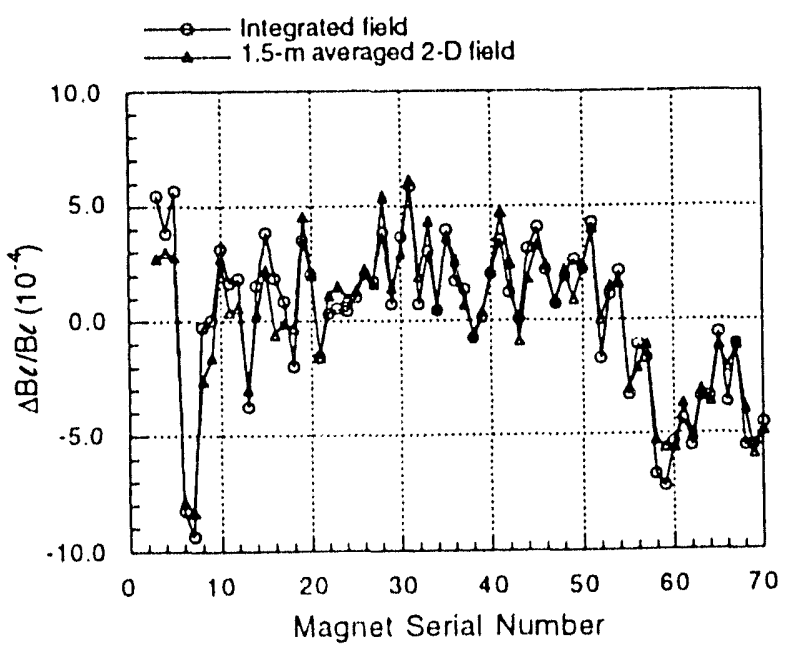

Fig. 3. Integrated and 2-D field strengths for each dipole relative to the reference dipole, $\triangle B C / B C$ and $\triangle B_{2}, B_{4}$ ) 


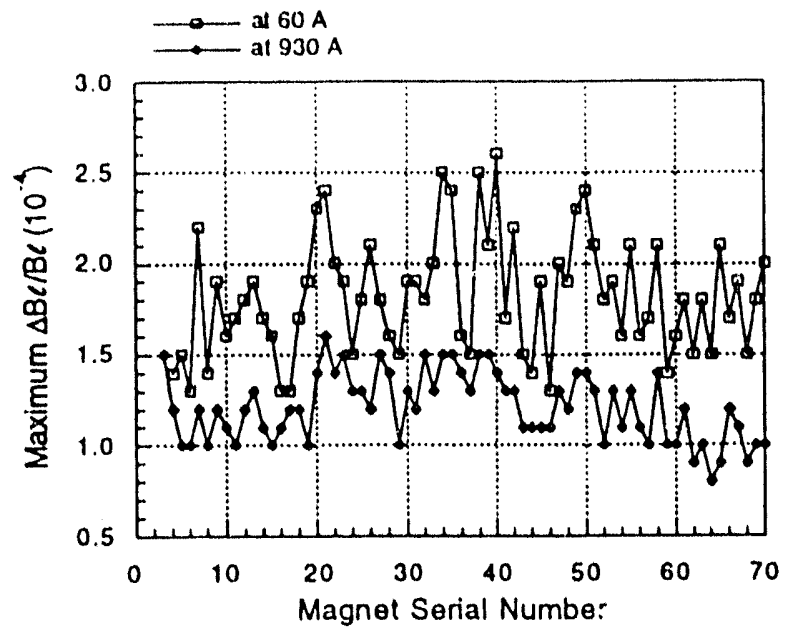

Fig. 4. Maximum $\triangle B C / B C$ and $\triangle B_{\alpha} / B_{0}$ within $r= \pm 30 \mathrm{~mm}$ at $39 \mathrm{~A}$ and 930 $A$. The data are relative values in the middle of the pole gap for each dipole, as shown in Fig. 2.

Shown in Fig. 4 is the maximum $\triangle B / B \ell$ relative to the middle of the pole gap for all dipoles within the radial displacement of $\pm 30 \mathrm{~mm}$ at the two excitation currents. Except for a few magnets, the values of $\triangle B \ell / B \ell$ are within $5 x$ $10^{-4}$.

\section{QUADRUPOLE AND SEXTUPOLE MAGNETS}

The cross sections of the quad and sext magnets are shown in Fig. 5 and Fig. 6 . The quad has pole-end bevels of $30^{\circ}$ on five laminations. The magnetic lengths of the quad and sext are $0.501 \mathrm{~m}$ and $0.122 \mathrm{~m}$, respectively. As in the case of the dipole magnet, the fiducial ball bases are welded on top of the magnets. Because of the relatively short magnetic length for the sext magnet, only one ball base is installed.

A rotating coil system is used for the magnetic measurements wherein the rotating coil is aligned to the magnetic axis [2]. As the magnets are measured the roll angles and the positions of the fiducial balls on the magnets are also measured for the survey and alignment of the magnets.

In Table 3 magnetic measurement data for all quad and sext magnets are summarized along with the allowed tolerances of the ring. The average residual field for the quads is $6.9 \mathrm{G}(2.2$ $x 10^{-2}$ of the field at $39 \mathrm{~A}$ ), which makes the rms of $\angle \triangle B^{\prime} \angle B^{\prime} \subset>$ for the quad at $39 \mathrm{~A}$ relatively large.

Systematic (average) and random ( $\mathrm{rms}$ ) multipole cefficients for the quads are shown in Fig. 7. The skew and other normal coefficients less than $1 \times 10^{-4}$ are not included

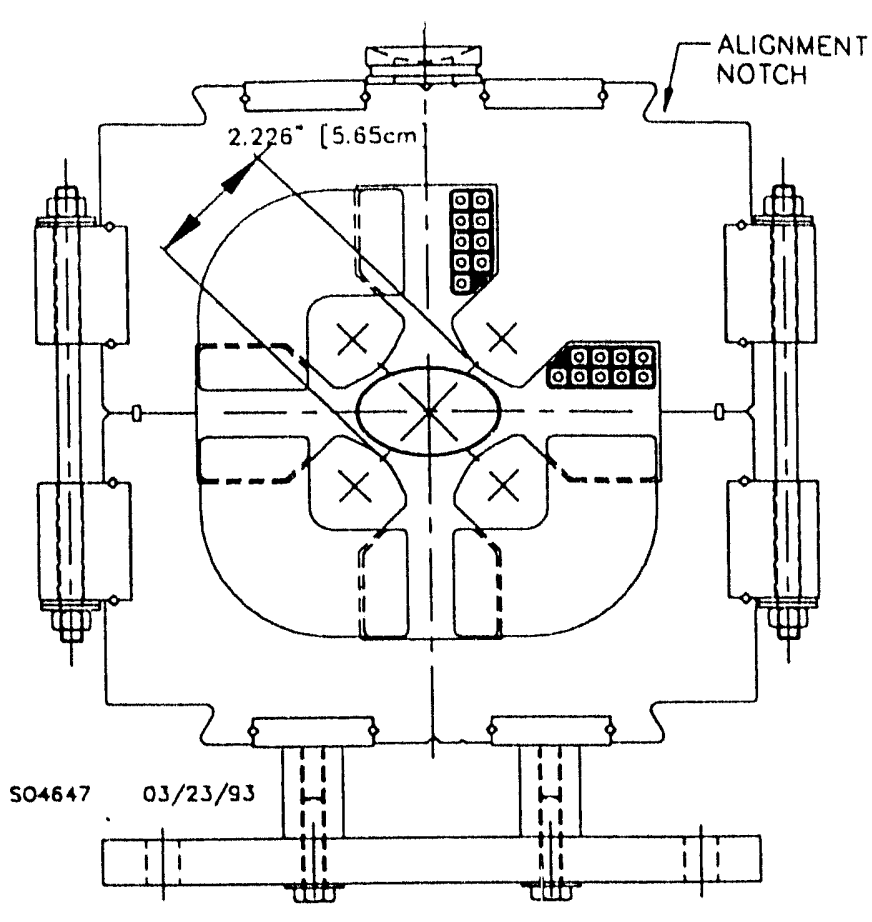

Fig. 5. Cross section of the quad.

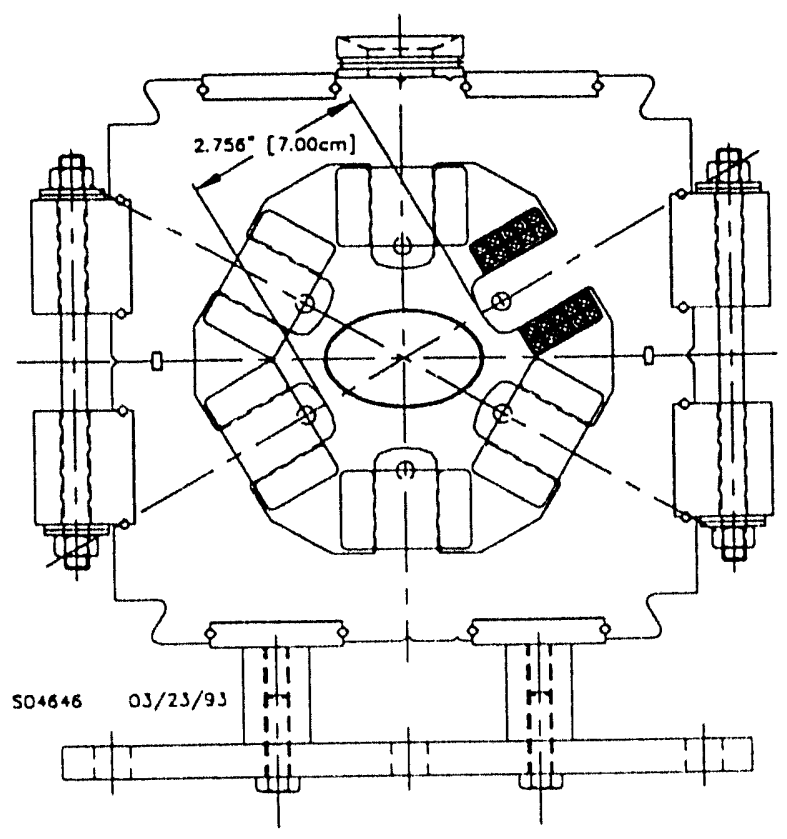

Fig. 6. Cross section of the sext.

here. Since the rotating coil axis is aligned to the magnetic axis, the dipole component vanishes. The measurement data for the pre-production quad have shown that the end bevels 
increased $b_{5}$ (dodecapole) by $2.7 \times 10^{-3}$ with respect to an unbeveled case, while decreasing by (20-pole) by $3.1 \times 10^{-4}$.

Systematic and random multipole coefficients for the sexts are shown in Fig. 8. The magnet does not have pole-end bevels, which makes $r$; a relatively large negative value. Since the rotating coil axis is aligned to the magnetic axis, the quadrupole coefficient vanishes. The measured dipole field of the magnet was less than $0.1 \mathrm{G}$.

TABLE 3

TOLERANCE AND MEASURED RMS FOR ALL IS QUAD AND SEXT MAGNETS

\begin{tabular}{cccc}
\hline & $\begin{array}{c}\text { Allowed } \\
\text { Tolerance }\end{array}$ & $\begin{array}{c}\text { Measured } \\
\text { rms }\end{array}$ \\
\hline Quad & $\left\langle\Delta B^{\prime} L B^{\prime} C>\right.$ & $2.0 \times 10^{-3}$ & $\begin{array}{c}5.1 \times 10^{-4} @ 600 \mathrm{~A} \\
3.0 \times 10^{-2} @ 39 \mathrm{~A}\end{array}$ \\
& $\mathrm{~b}_{1}$ & $2.5 \times 10^{-3}$ & $0.45 \times 10^{-4}$ \\
Sexs & $\left\langle\Delta \mathrm{B}^{\prime \prime} / \mathrm{B}^{\prime \prime} \mathrm{C}\right\rangle$ & 0.1 & $1.4 \times 10^{-3}$ \\
\hline
\end{tabular}

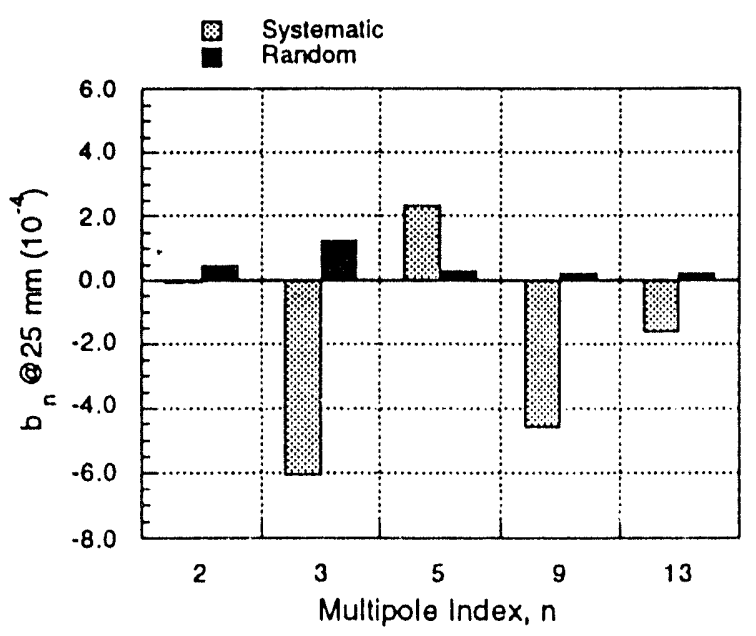

Fig. 7. Systematic and random multipole coefficients for the quads.

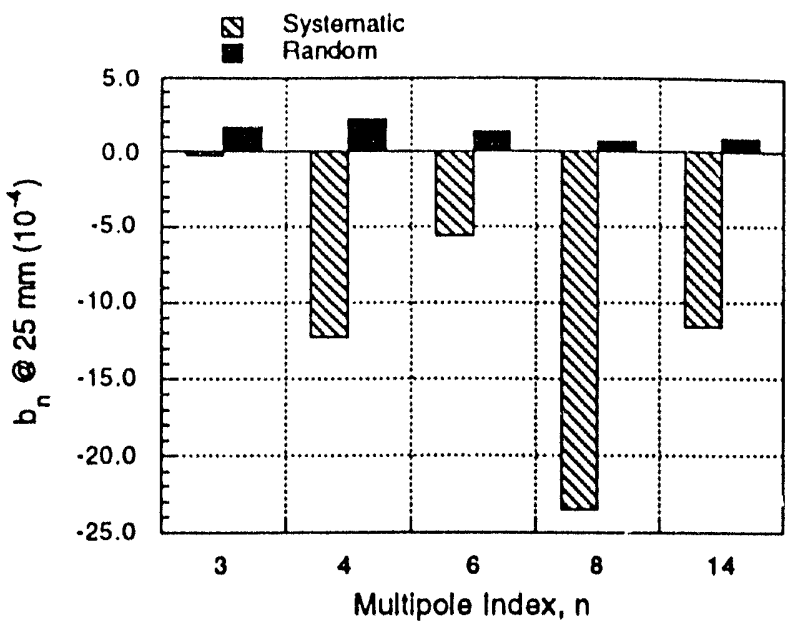

Fig. 8. Systematic and random multipole coefficients for the sexts.

\section{CONCLUSIONS}

The rms of the magnetic field strength and field quality for the ring magnets meet the allowed tolerances for the IS. Rms measurements of dipole and quad field strengths are $3.4 \times 10^{-4}$ and $5.1 \times 10^{-4}$, respectively. The rms for the sexts, which has relatively loose tolerance requirements, is $1.4 \times 10^{-3}$. For the quad and sext magnets, the positions of the magnetic axes and roll angles are also measured during the magnetic measurements.

\section{REFERENCES}

[1] "7-Gev Advanced Photon Source, conceptual design report," Argonne National Laboratory, ANL-87-15, 1987.

[2] S. H. Kim, C. Doose, R. Hogrefe, K. Kim, and R. Merl, "The magnet measurement facility for the Advanced Photon Source," in these proceedings.

[3] K. Kim, S. H. Kim, K. M. Thompson and L. R. Turner, "Design and tests of the injector synchrotron magnets for the 7-GeV Advanced Photon Source," Proc. of the 1993 Particle Acc. Conf., Washington, DC, May 1993.

\section{DISCLAIMER}

This report was prepared as an account of work sponsored by an agency of the United States Government. Neither the United States Government nor any agency thereof, nor any of their employees, makes any warranty, express or implied, or assumes any legal liability or responsibility for the accuracy, completeness, or usefulness of any information, apparatus, product, or process disclosed, or represents that its use would not infringe privately owned rights. Refer ence herein to any specific commercial product, process, or service by trade name, trademark, manufacturer, or otherwise does not necessarily constitute or imply its endorsement, recommendation, or favoring by the United States Government or any agency thereof. The viliws and opinions of authors expressed herein do not necessarily state or reflect those of the United States Government or any agency thereof. 
